\title{
Presença do arilo na produção de mudas de Maytenus ilicifolia
}

\author{
Presence of arils over Maytenus ilicifolia seedlings production
}

\author{
Márcio Paim Mariot ${ }^{1}$ Rosa Lia Barbieri ${ }^{2}$ Cledimara Sinigaglia ${ }^{3}$ \\ Lúcia Helena Bento $^{3}$ Márcia Vaz Ribeiro ${ }^{4}$
}

\section{RESUMO}

A propagação da espinheira-santa (Maytenus ilicifolia) é feita por sementes, sendo indicada a retirada do arilo para a semeadura, prática que demanda muito tempo e mão-deobra. $O$ experimento foi instalado com o objetivo de avaliar a influência do arilo na produção de mudas de espinheira-santa. Foram utilizados dois acessos do Banco Ativo de Germoplasma de M. ilicifolia da Embrapa Clima Temperado, 30 e 91. Os tratamentos utilizados foram: 11 - sementes com arilo retirado logo após a abertura das cápsulas (armazenadas em câmara fria sem arilo); T2 - sementes com arilo retirado no dia da semeadura (armazenadas em câmara fria com arilo) e T3 - sementes sem a retirada do arilo. Foram avaliados: dias da semeadura à emergência (DSE); porcentagem de emergência em canteiros (\%EC); comprimento da parte aérea (CPA); diâmetro da base do caule $(D B C)$ e número de folhas/planta $(N F)$. A presença do arilo nas sementes de M. ilicifolia não influenciou os caracteres DSE, \%G, DBC e NF, podendo influenciar apenas no caráter comprimento da parte aérea, dependendo da constituição genética da população, não sendo necessária a retirada do arilo para a semeadura.

Palavras-chave: Celastraceae, sementes, caracteres morfológicos, caracteres fisiológicos.

\section{ABSTRACT}

Maytenus ilicifolia is propagated by seeds and it is indicated to remove arils before sowing, what requires much time and work. An experiment to evaluate the influence of arils over seedlings production was installed in Embrapa Clima Temperado, in Pelotas, RS. Two accesses (30 and 91) of M. ilicifolia Gene Bank were used. The treatments were: $T 1$-seeds with arils removed immediately after the capsules (fruits) being opened (stored in cold room without arils); $T 2$ - seeds with arils removed in the sowing's day (stored in cold room with arils); T3 - seeds with arils. The characters evaluated were: days of sowing to emergence (DSE); emergence percentage (\%G); aerial part length (CPA); stem base diameter $(D B C)$ and number of leaves/seedling $(N F)$. The arils in the seeds of $M$. ilicifolia did not influence the characters DSE, $\% G, D B C$ e NF, but can influence the aerial part length (CPA), depending on the population genetic constitution. It is not necessary to remove the seeds arils to sowing of $\mathbf{M}$. ilicifolia.

Key words: Celastraceae, seeds, morphological characters, physiologic characters.

Maytenus ilicifolia Mart. ex Reiss., popularmente conhecida como espinheira-santa ou cancorosa, é uma espécie nativa do Brasil, pertencente à família Celastraceae, com propriedades terapêuticas para problemas de gastrite e úlcera gástrica comprovadas (CARLINI, 1988). Ela é considerada prioritária para coleta, conservação e caracterização, devido à erosão genética que vem sofrendo (VIEIRA \& SILVA, 2002). A Embrapa Clima Temperado

\footnotetext{
${ }^{1}$ Engenheiro Agrônomo, MSc, professor do Conjunto Agrotécnico "Visconde da Graça", Universidade Federal de Pelotas (UFPel), doutorando em Agronomia (Fitomelhoramento), UFPel. Rua Voluntários da Pátria, 362, 96015-730, Pelotas, RS. E-mail: mariot@ufpel.tche.br. Autor para correspondência.

${ }^{2}$ Biólogo, Doutor, Pesquisador da Empresa Brasileira de Pesquisa Agropecuária (Embrapa) Clima Temperado, Pelotas, RS.

${ }^{3}$ Biólogo, Estagiário da Embrapa Clima Temperado, Pelotas, RS.

${ }^{4}$ Biólogo, Professor do Departamento de Botânica, UFPel.
} 
possui um Banco Ativo de Germoplasma (BAG) desta espécie e, em conjunto com a Universidade Federal de Pelotas vem conservando e caracterizando os acessos (BENTO et al., 2003).

As sementes de espinheira-santa são envoltas pelo arilo, excrescência carnosa que se forma no funículo ou no hilo (VIDAL \& VIDAL, 2000) que, para esta espécie, é de coloração branca e fica exposta quando o fruto (cápsula) maduro abre-se (CARVALHO-OKANO, 1992). Elas são consideradas ortodoxas, podendo ser conservadas em câmara fria (ROSA \& BARROS,1999; EIRA et al.,1995). O número de sementes por fruto varia de 1 a 4, tendo sido observada uma variabilidade altamente significativa para este caráter dentro da espécie (MARIOT et al., 2003).

Em M. ilicifolia, as sementes representam a forma mais viável de propagação (NEGRELLE et al., 1999). Para a semeadura desta espécie, vários autores recomendam a retirada do arilo logo após a abertura das cápsulas (MAGALHÃES, 2003; SCHEFFER, 2001; NEGRELLE et al.,1999). Esta prática demanda muito tempo e mão-de-obra, nem sempre disponível nas propriedades que produzem mudas desta espécie. Neste sentido, o presente trabalho teve como objetivo avaliar a influência do arilo presente na semente sobre caracteres morfofisiológicos importantes na obtenção de mudas de espinheira-santa.

Foram utilizadas sementes de dois acessos do BAG de M. ilicifolia: acessos 30 e 91, oriundos, respectivamente, dos municípios de Piratini e Farroupilha. Todas as sementes utilizadas foram armazenadas em câmara fria a uma temperatura de 4- $6^{\circ} \mathrm{C}$, sendo que o acesso 30 ficou nestas condições por 60 dias e o acesso 91 por 30 dias. Os tratamentos utilizados foram: T1 - sementes com arilo retirado logo após a abertura das cápsulas e posteriormente armazenadas em câmara fria sem arilo; T2 - sementes com arilo retirado no dia da semeadura, após armazenamento em câmara fria com arilo) e T3 sementes com arilo.

$\mathrm{O}$ experimento foi instalado em telado, em Pelotas, RS, em 10 de fevereiro de 2003, em canteiros móveis de 72 células. Os caracteres avaliados foram: dias da semeadura à emergência, porcentagem de emergência em canteiro, comprimento da parte aérea, diâmetro da base do caule e número de folhas por planta. As avaliações para todos os caracteres, com exceção de dias da semeadura à emergência, foram realizadas 90 dias após a semeadura, em maio de 2003. O delineamento experimental foi de blocos casualizados, com quatro repetições e dez plantas por parcela. A análise estatística constou de análise da variância, com significância pelo teste $\mathrm{F}$ a $5 \%$ de probabilidade, e comparação entre médias através do teste de Tukey a 5\% de probabilidade, sendo realizada através do programa SAS (SAS Institute, 1991). Os dados referentes ao caráter diâmetro da base do caule foram transformados para logaritmo da base 10 .

Para o acesso 30, houve diferença significativa apenas para o caráter comprimento da parte aérea, em que as plantas dos tratamentos que envolveram a retirada do arilo, tanto no momento de abertura das cápsulas quanto no dia da semeadura, apresentaram maior estatura do que as do tratamento em que o arilo não foi retirado (Tabela 1). Para o acesso 91, não houve diferença significativa entre os

Tabela 1 - Caracteres morfo-fisiológicos de plântulas dos acesso 30 e 91 do Banco Ativo de Germoplasma de Maytenus ilicifolia em diferentes condições de semeadura.

\begin{tabular}{|c|c|c|c|c|c|c|}
\hline \multirow{2}{*}{ Tratamento } & \multicolumn{6}{|c|}{ Caracteres $^{1}$} \\
\hline & Acesso 30 & $\mathrm{CPA}(\mathrm{cm})$ & $\mathrm{DBC}(\mathrm{mm})$ & $\mathrm{NF}$ & DSE & $\mathrm{EC}(\%)$ \\
\hline 1 & & $3,47 \mathrm{a}^{2}$ & $0,77 \mathrm{a}$ & $3,42 \mathrm{a}$ & $28,52 \mathrm{a}$ & $47,75 \mathrm{a}$ \\
\hline 2 & & $3,32 \mathrm{a}$ & $0,77 \mathrm{a}$ & $3,30 \mathrm{a}$ & $29,87 \mathrm{a}$ & $66,50 \mathrm{a}$ \\
\hline 3 & & $2,89 \mathrm{~b}$ & $0,73 \mathrm{a}$ & $3,10 \mathrm{a}$ & $34,89 \mathrm{a}$ & $63,50 \mathrm{a}$ \\
\hline CV $(\%)$ & & 4,64 & 4,75 & 6,14 & 10,41 & 42,95 \\
\hline & Acesso 91 & & & & & \\
\hline 1 & & $4,11 \mathrm{a}$ & $1,05 \mathrm{a}$ & $3,90 \mathrm{a}$ & $29,35 \mathrm{a}$ & $53,00 \mathrm{a}$ \\
\hline 2 & & $4,25 \mathrm{a}$ & $1,08 \mathrm{a}$ & $3,80 \mathrm{a}$ & $27,66 \mathrm{a}$ & $57,25 \mathrm{a}$ \\
\hline 3 & & $3,74 \mathrm{a}$ & $1,06 \mathrm{a}$ & $3,72 \mathrm{a}$ & $31,40 \mathrm{a}$ & $49,50 \mathrm{a}$ \\
\hline $\mathrm{CV}(\%)$ & & 5,82 & 8,45 & 12,77 & 12,13 & 35,88 \\
\hline
\end{tabular}

${ }^{1} \mathrm{CPA}$ - comprimento da parte aérea; DBC - diâmetro da base do caule; NF - número de folhas; DSE - dias da semeadura à emergência e EC (\%) - porcentagem de emergência em canteiros.

${ }^{2}$ Médias com as mesmas letras nas colunas não diferem significativamente pelo teste de Tukey a $5 \%$ de probabilidade de erro. 
tratamentos para nenhum dos caracteres. Os resultados mostram que o arilo pode influenciar no comprimento da parte aérea, dependendo da constituição genética da população.

Em trabalho desenvolvido com M. boaria, CABELLO \& CAMELIO (2003) observaram que o arilo inibiu a germinação das sementes, ao contrário do que foi observado neste trabalho, em que a presença do arilo não influenciou a germinação de sementes de espinheira-santa. Os autores utilizaram areia fina para remover o arilo, o que pode ter auxiliado na quebra de dormência, não sendo, portanto, o arilo em si que inibiu a germinação das sementes daquela espécie. Pelos dados evidenciados no presente trabalho, não há necessidade de se retirar o arilo para semeadura de $\boldsymbol{M}$. ilicifolia, oposto ao sugerido por MAGALHÃES (2003), SCHEFFER (2001) e NEGRELLE et al. (1999), o que facilitará a produção de mudas desta espécie, pela redução da mão-de-obra e do tempo para o preparo das sementes para semeadura. Entretanto, não há evidência da influência do arilo quando as sementes forem armazenadas com esta estrutura em câmara fria por um período maior do que o utilizado neste trabalho. Neste sentido, no que se refere ao armazenamento por um período maior do que 60 dias, ainda é recomendada a retirada do arilo das sementes e posterior armazenamento sob condições estabelecidas por EIRA et al. (1995) e ROSA \& BARROS (1999).

A presença do arilo nas sementes de $\boldsymbol{M}$. ilicifolia pode influenciar apenas o caráter comprimento da parte aérea, dependendo da constituição genética da população, o que sugere a não necessidade de retirada do arilo para semeadura.

\section{REFERÊNCIAS BIBLIOGRÁFICAS}

BENTO, L.H.G. et al. Organização do banco ativo de germoplasma de Maytenus ilicifolia na Embrapa Clima Temperado. In: ENCONTRO SUL-BRASILEIRO DE PLANTAS MEDICINAIS, 2003. Curitiba, PR. Anais... Curitiba : PUCPR, 2003. 1 CD-ROM.

CABELLO, A.; CAMELIO, M.E. Germinación de semillas y producción de plantas de maitén (Maytenus boaria Molina). Capturado em 20 set. 2003. On line. Disponível na Internet http:// www.uchile.cl/facultades/cs_forestales/publicaciones/cesaf/n6/3.htm.
CARLINI, E.A. (coord.). Estudo da ação antiúlcera gástrica de plantas brasileiras: Maytenus ilicifolia (espinheira-santa) e outras. Brasília : CEME/AFIP, 1988. $87 \mathrm{p}$.

CARVALHO-OKANO, R.M. Estudos taxonômicos do gênero Maytenus Mol. emend. Mol. (Celastraceae) do Brasil extraamazônico. 1992. 253f. Tese (Doutorado em Ciências: Biologia Vegetal) - UNICAMP.

EIRA, M.T.S. et al. Comportamento fisiológico de sementes de espinheira-santa (Maytenus ilicifolia) no armazenamento. Horticultura Brasileira, Brasília, v.13, n.1, p.32-34, 1995.

MAgalhães, P.M. Agrotecnologia para espinheirasanta. Capturado em 20 set. 2003. On line. Disponível na Internet http://www.cpqba.unicamp.br/plmed/artigos/ agroespsant.htm.

MARIOT, M.P. et al. Dissimilaridade entre genótipos de Maytenus ilicifolia (espinheira-santa) de uma população do Rio Grande do Sul. In: CONGRESSO BRASILEIRO DE MELHORAMENTO DE PLANTAS, 2., 2003, Porto Seguro, BA. Anais... Porto Seguro : Sociedade Brasileira de Melhoramento de Plantas, 2003. 1 CD-ROM.

NEGRELLE, R.R.B. et al. Tecnologia de produção de sementes de espinheira-santa (Maytenus ilicifolia Mart. ex Reiss. Celastraceae). Revista Brasileira de Sementes, v.21, n.1, p.7681, 1999.

ROSA, S.G.T.; BARROS I.B.I. Behavior of Maytenus ilicifolia seeds in different periods and storage conditions. Acta Horticulturae, n.502, p.249-254, 1999.

SAS INSTITUTE. SAS/STAT user's guide. Cary : Statistical Analysis System Institute, 1991. 416p.

SCHEFFER, M.C. Sistema de cruzamento e variação genética entre populações e progênies de espinheira-santa. 2001. 104f. Tese (Doutorado em Engenharia Florestal) - Curso de Pósgraduação em Engenharia Florestal, Universidade Federal do Paraná.

VIDAL, W.N.; VIDAL, M.R.R. Botânica: organografia; quadros sinóticos ilustrados de Fanerógamos. 4.ed. Viçosa : Universidade Federal de Viçosa, 2000. 124p.

VIEIRA, R.F.; SILVA, S.R. (Coord.). Estratégias para conservação e manejo de recursos genéticos de plantas medicinais e aromáticas: Resultados da $1^{\underline{a}}$ reunião técnica. Brasília : Embrapa Recursos Genéticos e Biotecnologia, Instituto Brasileiro do Meio Ambiente e dos Recursos Naturais Renováveis (Ibama), Conselho Nacional de Desenvolvimento Científico e Tecnológico (CNPq), 2002. $184 \mathrm{p}$. 